\title{
Migration Related Socio-cultural Changes and e-Learning in a European Globalising Society
}

\author{
Johan Leman $\cdot$ Ann Trappers $\cdot$ Emily Brandon $\cdot$ Xavier Ruppol
}

Published online: 8 November 2007

(c) Springer Science+Business Media B.V. 2007

\begin{abstract}
OECD figures (1998-2002) reveal a sharply increasing flow of foreign workers into European countries. Ethnic diversification has become a generalized matter of fact. At the same time, rapidly developing technology and 'intellectual globalization' processesthe world wide web-have also become a reality. This complex cluster of changes has an impact on the perceptions of the self and of the other. Multilayered belongings and paradoxical meanings enter into interethnic relations in sometimes most surprising and unpredictable ways from outside of the boundaries of local communities. But the developments also create new and very positive opportunities for education/schooling and social cohesion. The paper critically examines this changing context and also Europe's educational responses to the new challenges: the European Socrates programme, the initiatives in the field of intercultural citizenship education and the issue of combating deprivation.
\end{abstract}

Keywords World wide web · Diversity - Multiple belonging · Education · Europe

\section{Introduction}

The "global society (as) a network society" (Castells 1996), with its "global interconnectedness, suggesting a world full of movement", is a complex mixture of processes, which often also produce conflicts, disjunctures and new forms of inequality (Giddens

J. Leman $(\bowtie) \cdot$ A. Trappers $\cdot$ E. Brandon

IMMRC, Social and Cultural Anthropology, Faculty of Social Sciences,

Katholieke Universiteit Leuven, Leuven, Belgium

e-mail: johan.leman@soc.kuleuven.be

\author{
A. Trappers \\ e-mail: ann.trappers@soc.kuleuven.be \\ E. Brandon \\ e-mail: embrandon@gmail.com \\ X. Ruppol \\ Learning Services branch, IBM, Brussels, Belgium \\ e-mail: Xavier_Ruppol@be.ibm.com
}


1999, pp. 15-18; Carling 2006). At least as important as economic factors are the social "contacts and linkages" (Xavier Inda and Rosaldo 2001, p. 2), and their impact on the creation and vehiculation of cultural meanings, including religious and ethnic emblems.

Our paper will discuss the socio-cultural challenges for education in Europe as a globalising society, with an eye on the current praxis in the E.U. countries and at the institutional E.U. commission level. The first paragraphs will develop the current developments of more ethnically and socially diversified migrations: the facts. Afterwards, we look at the consequences of the new technological environment and of the increasing impact of the World Wide Web in Europe on the migration related interethnic relations and social cohesion. Our thesis will be that the new ICT technological space may be, in theory, as positive for the lowly skilled as for the highly skilled migrants, but that Europe invests most in the top-down approach.

\section{An Increasing Impact of 'Skilled' Migrations Inside and into Europe}

Work permit statistics show a continuous flow of foreign workers into European countries. In some countries the figures have increased sharply in the 5-year period from 1998 to 2002, as OECD figures reveal. Examples include Hungary (22,600 incoming foreign workers in 1998 as opposed to 49,800 in 2002), Italy (21,600 in 1998, 139,100 in 2002) and Ireland (5,700 incoming non-EU workers in 1998 and no less than 40,300 in 2002) (OECD/SOPEMI 2005).

Foreign workers do not necessarily relocate permanently; many work seasonally in tourism or agriculture. For instance, the Spanish labour quota system was set at 13,762 temporary foreign workers in 2003. So-called "work and travel" programmes are also enjoying great popularity. In 2002, for example, the United Kingdom welcomed 41,700 working holidaymakers (OECD/SOPEMI 2005).

Throughout Europe, migrations and ethnic diversification have become a matter of fact. The new post-guestworker (Gastarbeiter) migrations are characterized by diversification and fragmentation. The increasing diversity of migratory flows can be inferred very clearly from the fact that for many countries the top- 15 of incoming nationalities has a composition that is increasingly different from the top-15 of the pre-existing foreign population stock, as well as from the fact that the number of migrants that OECD statistics list under "other countries" is relatively high and currently increasing in several countries. An example from Norway can illustrate this: with over 25,000 representatives, the Swedes were the most numerous foreign nationality in Norway in 2002. Yet inflow figures show a drop in the annual inflow of Swedes from 6,000 in 1998 to 2,900 in 2002. Conversely, the inflow of Somalis, albeit much smaller, has doubled over the same period (Ibid., statistical annex).

In this section we develop a focus on issues specifically related to the rapidly-developing technology and "intellectual" globalization processes, referring only briefly to other important realities, such as the refugee issue.

\section{Refugees}

Any discussion of "post-guestworker migration" in Europe, today, must take into account the refugee issue. The major feature of European, and indeed global, migration trends has been the increase in refugee migrations since the middle of the 1980s. Particularly fastgrowing has been the category of refugees who fall outside the definition of refugee established by the 1951 UN Convention and therefore must remain either asylum seekers 
or displaced persons (King 2002, p. 96). The OECD asylum seeker figures for many (but not all) European countries reveal a significant increase in the number of applicants from 'other countries', suggesting that the composition of the flows is becoming more diverse. In Sweden, asylum seekers from 'other countries' than the top-15 nationalities went up from 3,452 in 1994 to 12,297 in 2003 (OECD/SOPEMI 2005, statistical annex). In Switzerland, their numbers increased from 2,559 in 1994 to 10,454 in 2003. In both cases, the total growth in asylum applications over the years 1994-2003 was not proportionate to this increase (from 18,677 to 31,360 in Sweden and from 16,134 to 21,051 in Switzerland).

Even if the profile of the refugees is already more a socially mixed one than the Gastarbeiter profile, it is on the more typically "skilled" migrations that we want to focus here. And there we distinguish between the students, the brain migrations, and the care migrations, and-indirectly and partially—also the long-term tourist migrations.

\section{Students}

The 2004 edition of SOPEMI recognizes the "spectacular increase in inflows and stocks of foreign students" (OECD/SOPEMI 2005, statistical annex, p. 36) as a significant migration trend, and one which is encouraged by the fact that several OECD countries have introduced policies that facilitate the entry of foreign students. Eurostat figures for 19 European countries, covering the period 1998-2003, show that the total number of foreign students in tertiary education is on the increase in all countries concerned. Some nationalities are more strongly represented as students than as 'ordinary' incoming migrants.

Although the majority of foreign students in higher education in Europe still come from another European country (IOM 2003, p. 308), there are foreign students in Europe of nearly every conceivable nationality. Certain nationalities are clearly on the rise. The number of Asian students, particularly those of Chinese origin, is growing rapidly in several countries-for example: over 40,000 Chinese students were officially registered in the UK in 2003/2004, a massive increase compared to the previous academic year, and one that makes them the largest group after the EU citizens (Shen 2005, p. 430). Their numbers are also quickly increasing in Denmark (from around 100 in 1999 to around 1,000 in 2003 according to Eurostat's isced5_6 database) and Germany (from around 5,000 to around 20,000 in the same period), but at the same time Chinese migrants had not yet made it into the top-15 of the most numerous nationalities in the migrant inflows in either country according to OECD figures.

However, in quite a few countries, the largest incoming migrant group is but weakly represented in the foreign student population. In 2002 this was the case, for example, for Ecuadorians in Spain, Iraqis in Denmark, Romanians in Italy and Ukrainians in Portugal. There are a number of possible explanations, one being that study abroad is simply not a viable strategy for many of these individuals. Often, immigrants from low-income countries take up lower-ranking jobs for which they are better paid than for more prestigious positions in their own country (King 2002, p. 95). Migration strategies have become much more diverse than in the traditional guest worker periods.

\section{Brain Migrants}

Africa, a neighbouring continent to Europe, is another significant source of migrants, including a significant number of individuals who come seeking educational opportunities. "Africa has a higher proportion of expatriate students than other regions in the world 
(about 10\%). A third of these go to France, where they account for $75 \%$ of students from developing countries and $12 \%$ of the total number of doctorates awarded in France" (Barré et al. 2003, p. 128). In France, "the research sector has a relatively high percentage of foreign-born workers. A majority come from developing countries, and these are mainly concentrated in the academic sector, whereas most foreigners born in OECD countries work in other sectors (trade, finance, management etc.)" (Ibid. 2003, p. 125). Given the necessity for Europe to comply with the Lisbon norms, one can conclude that such phenomena will only increase in all European countries, with highly educated migrants coming in from Asia and Latin America as well.

\section{Care Migrants}

The health care sector, and nursing in particular, is another important sector in which foreign workers are strongly present in several OECD countries today. Countries in which foreigners are currently over represented in health care include Ireland, Norway, Sweden and the United Kingdom (OECD/SOPEMI 2005, p. 66). In the United Kingdom many medical and care professions, including "all registered nurses and midwives" are mentioned on the Shortage Occupation List (http://www.hsmp-services.co.uk/shortage_occupations. html) of the Highly Skilled Migrant Programme. This increasing migration of health care professionals is related also to the growth in independent female migration (see also King 2002, pp. 97-98).

\section{Tourism}

Worldwide, in 2004, 763.3 million tourist arrivals occurred, more than half of which (431.1 million) in Europe. It is expected that European countries will welcome 717 million tourists in 2020, Eastern Asia and the Pacific 397 million and the Americas 282 million. This suggests a quickly rising movement of people in Europe, apart from the traditional migratory movements. Especially in the Mediterranean, this tourism is not only daily tourism, but it also comprises stays much longer than 1 month (see e.g. Vanlangendonck 2002). It drastically changes entire regions, which welcome the substantial financial input to the region (www.world-tourism.org).

\section{Multiple Paradoxical Identifications and Learning}

The ever growing diversification, ${ }^{1}$ the presence of higher skilled migrants of various parts of the world, and their new, technologically more developed ways of communication and mobility, have an impact on the perceptions of the self and of the other (i.e. on the interethnic relations). The classic image of the 'uprooted' and 'replanted' migrant is no longer a valid metaphor of how immigration is experienced. Increasingly, migrants divide their lives, be it physically, mentally, or both. Therefore, a person may feel a sense of belonging to two or more places at once and identify with several different groups.

\footnotetext{
1 Vertovec (2006) mentions 'super-diversity' as characteristic for the situation in European cities in the last decade, "a notion intended to underlie a level and kind of complexity surpassing anything previously experienced". For a similar notion, see Miyares (2004) and the notion of 'hyperdiversity'.
} 
In order to capture such phenomena, terms such as "transnational" (Basch et al. 1995) and "hybrid" identities have been coined. These transnational and hybrid identities make up both a source of inspiration and a fertile soil for various intercultural concepts (see also Grillo 1998, p. 232). They clearly demonstrate that identity, even ethnic identification, is by no means fixed. It is a relationship, something which is constructed in the process of social interaction, which implies that identity is necessarily dialogical. As Baumann formulates it: "Multicultural society is not a patchwork of five or ten fixed cultural identities, but an elastic web of crosscutting and always mutually situational, identifications" (Baumann 1999, p. 118). Mobility between the place of origin of the parents and the place of settlement is to some degree maintained.

This context of huge diversification, of more skilled migrant family cultures and migrant environments, of increasing intra-European transnationalism, is reinforced by still another phenomenon: the development of the WWW space and its WWW culture, today principally among youngsters. "Globalization decisively unmakes the coherence that the modernist project of the 19th- and 20th-century nation-state promised to deliver-the neat fit between territory, language, and identity" (Suarez-Orozco and Qin-Hilliard 2004, p. 3). The WWW space leads to still more complex articulations in the possible identification processes of the social selves. It also creates new opportunities for learning, from formal education to reaching new audiences with information. We will explore these further in a later section.

\section{Moving in a New Space of Information and Communication}

The environment of interethnic relations, and of perceptions of "self" and of "other", is changing dramatically due to the increasing impact of the World Wide Web. The impact of the global ICT space in the Western world, more specifically in Europe, will be illustrated by means of a selection of everyday experiences that will be immediately recognizable to readers.

Prior to 1975 , most people could only dream of a personal computer. Those were only available to a small group of enthusiastic amateurs. By 1980, 2 million personal computers had been sold. In 1995, more than 150 million personal computers were in use. In the year 2004, 173 million computers were sold in the entire world (Reimer 2005). The NUA surveys, referencing to the Nielsen Netratings (http://www.nua.com/surveys), show that, in the third quarter of 2002, 563 million people had access to the internet, growing to 580 million in 2003. The NUA survey further reports that the U.S. holds the first place worldwide (29\% of the global internet access), followed by Europe, Asia-Pacific and Latin America (respectively 23\%, $13 \%$ and $2 \%$ of worldwide global internet access). The fragmented diaspora communities, newly arrived in the Western world, are quick to use the internet in order to stay connected with each other.

In telephony as well, there are interesting evolutions under way. "The cost of telephone calls has plummeted, owing to satellite communication technology. For example, the price of a 3-min phone call from New York to London dropped from about 250 dollars in 1930 to about 30 dollars in 1970, and to less than 20 cents by the year 2000" (Suarez-Orozco and Qin-Hilliard 2004, p. 17). Also VOIP technology allows users of programs such as Skype to talk to others throughout the world with other users by connecting through the internet, and for a small fee, to also make calls to traditional phone lines at impressivelylow rates. 
In the airline industry, low cost flights and a strong price competition have led to a more frequent use of planes, making it easier for people worldwide to stay physically connected as well. Mental, emotional and physical mobility and flexibility have become more common day practice than before, and this has a direct impact on social cohesion.

\section{European ICT Space and Social Cohesion}

In various European countries, the pre-reflexive consensus about social cohesion is under pressure. This consensus was based on the ideals of full employment and a common ideology of socio-Christian values. Both of those cornerstones are nowadays doubted. This may lead in some countries and in some cases to strong upsurges in political nationalism and religious fundamentalism.

At the median level (Barth 1994; Portes 1998, pp. 24-25), the global space of the World Wide Web has deposed associational life, the traditional mediator between the micro- and the macro-scale (Putnam 2001). The space between the "official incorporation" that emanates from the national and European institutions and the locally developing "relational embeddedness", has been filled by the globalized images of the World Wide Web and the media. This has dramatically changed the perception of the ethnically other and his "imagined community" (Anderson 1983), as well as self-perception. The images used are offered by a global space, the boundaries of which transcend the dynamics of both "incorporation" and of "local relational embeddedness". A typical example of today is the way the Muslims are perceived by many non-Muslim Europeans, and vice versa, or the way the Mohamed cartoons (2006) have been interpreted... Paradoxical, at times even strongly contradictory, meanings will enter into current interethnic relations in sometimes most surprising and unpredictable ways from outside of the boundaries of local communities.

However, the current developments may also create new and very positive opportunities for the relationship that may be seen between education/schooling and social cohesion (Heyneman 2003): “... the number of individuals who are affectively or legally transnational, with formal and emotional ties to more than one society, is likely to increase. In the era of belligerent and defensive nationalisms, 'divided' (or worse yet, multiple) loyalties often seemed almost treasonous. In the 21st century, such qualities represent valuable human capital" (Coatsworth 2004, p. 52).

\section{Consequences for Learning in Europe}

"We claim that two domains in particular will present the greatest challenges to schooling worldwide: the domain of difference and the domain of complexity" (Suarez-Orozco and Qin-Hilliard 2004, p. 3). From the above, it is clear that this has become European reality. We will now look at some of the most obvious educational challenges, and analyse how Europe copes with it.

Challenges due to the Impact of the ICT Environment

\section{ICT Culture in Young People's Lives}

According to a German Kinderwelt Survey (www.ip-network.com), in 2002 watching television was the usual pastime for $76 \%$ of German children between 6 and 13 years of 
age. The amount of time spent in front of the television increased with age. On average, German children between 3 and 13 watched television for 97 min every day.

In the US the Kaiser Foundation Report (www.kff.org) Generation M: Media in the lives of 8-18 year Olds (2005) has shown that youngsters between 8 and 18 spend $6 \frac{1}{2} \mathrm{~h}$ of each day using media, sometimes even two types of media at once (e.g., watching television while using the Internet). Sixty-three percentage of all 8-18-year-olds have a television set in their bedroom, $49 \%$ have a video game player there and $31 \%$ a computer. It seems likely that in Europe, classified behind the United States in ICT culture, a similar trend will manifest itself at least to some extent.

\section{'Multilayeredness' in the Representation of 'the Other' and 'the Self'}

Contrary to the expectations of a large share of Western public opinion, globalization will not lead to increasing homogenization or westernization. Rather, the existing localized diversity will be spread further around the world. Even though the medium will probably shape consumer attitudes worldwide in a homogenizing way, it will manifest itself as the carrier of cultural and ethnic contents.

The complexity created by the electronic global space at the median level can, just like increased mobility, lead to the development of multiple, paradoxical identities. There is not only a multilayered world in which supra-local images overlap with, enlarge or discolour local images; multilayered social and cultural identities also develop within one's personality. In one and the same person, there may be a local identity (where the adaptation to the local setting is affirmed), a transnational identity (with its loyalties and paradoxes) and a global identity (with its adaptation to a universal global).

\section{An Increased Complexification of Actual Language Use}

An additional educational challenge consists of not only finding a meaningful place for minority pupils' mother tongue (L1), but simultaneously raising awareness of the fact that the urbanized living environment has been rendered still more complex due to various sms and web youth language subcultures.

\section{Some Learning Opportunities that ICT Offers}

Multilayered identifications blur the distinction between the local and global. For the teacher and the student it becomes obvious, via e-learning, that various and different viewpoints are possible. This recognition of difference can potentially be valuable in itself, as it provides a challenge which requires innovation and effort from all sides. "Negotiating differences requires energy - the kind of energy that can be recycled and harnessed to bolster a cornerstone of human intelligence: the ability to consider multiple perspectives (Piaget 1936; Gardner 1999; Vygotsky 1978)" (Ibid., p. 5).

e-Learning can lead to a socialization in diversity, which is beneficial for education. Indeed, (a) mixing of local and global causes the easy homogenous answers to at least be reexamined if not replaced. The challenge inherent in having to compare ideas to very different other ideas, and trying to reconcile the variations, encourages more critical thinking and opens minds to new possibilities. (b) Schools and classroom learning are 
powerful for moulding social behaviours among students. So "immigrant" children can learn the receiving culture (towards assimilation) but at the same time, their presence can make a difference in the larger classroom setting, by increasing majority students' awareness to other cultures. In e-learning situations, the social influence is much less significant. There, ideas are exchanged in a more neutral environment, and in an online course, global and local don't even matter. Each person's input could be from across the street or across the ocean. One may think in terms of discussion groups on programs typically used by universities, such as Blackboard.

Does e-learning open new opportunities for intercultural and even cosmopolitan education? Having a more diverse student body, and correspondingly diverse parents, presents at least an opportunity for experiences, and areas of expertise that may be unfamiliar to be introduced. One may have a look at how higher education organizations are trying to incorporate diversity education and issues into their institutions. This is a wide-open field that is only beginning to blossom. One may see how an association of higher-education institutions focuses on addressing the issues of diversity and handles it successfully at college level, e.g. at http://www.aacu.org/meetings/diversityandlearning/index.cfm; http:// www.aacu.org/meetings/diversityandlearning/documents/DL_Final_Program.pdf.

e-Learning is not only about learning new 'neutral' technologies. The web creates a new space that adds new cultural realities and new important opportunities for social identification to the existing ones (cfr. Robertson 1992, p. 27) i.e. deterritorialized new networks of communities (e.g. European Islam; the Sikh communities outside Punjab; the Kurds or Berbers outside their countries of origin, inserted in the various countries of the West). Additionally, it is also about new ways of (understanding) communication between those concerned: the impact of the audio and visual dimensions is increasing in its relation to that of written language and written texts. This leads to a more complex and articulated "social fantasy" (Appadurai 1996, p. 54), that becomes part of the social praxis, today already very present in the lives of young people. This shift to the visual and auditive components in the perception of a more complexly articulated socio-cultural reality, with a decreasing impact of the more abstract language-morphological approach, together with its "shrinking of space and the shortening of time" (Xavier Inda and Rosaldo 2001, p. 6), is not value neutral for our perception of interethnic relations and social cohesion. It influences our perspective-taking (see also: http://www.hno.harvard.edu/gazette/1996/05.02/Voices AgainstVi.html).

Even if e-learning will make realities more complex, it will also be useful in the sense that it can simplify and increase the efficiency of the learning processes in various fields.

(a) If implemented in a compulsory school system, the e-learning opportunities may be useful in the struggle against inequality. The use of e-learning 'at school' provides at least some basic access to ICT to pupils who do not have this kind of access at home or in their spare time. Moreover, in the USA, non-traditional approaches to learning, made possible by the internet, open opportunities to students who must be absent for a while, and to nontraditional students, such as older, working people, young mothers, and others who cannot as easily attend a course offered on a university campus, or did not have the necessary study opportunities in the past. With this de-territorializing of education comes the potential, eventually, for people in any part of the world to join online courses, or to link classrooms together by teleconferencing technologies, in order to promote discussion and idea-sharing across national or cultural boundaries. When used adequately, ICT can also permit teachers to work with parents of immigrant children who had neither the opportunities nor the qualifications in the past to follow their children at school, at the condition of course that the parents have the technology themselves. 
(b) Many of the new technologies are targeting individual learning styles and delivering content in the most appropriate format for each learner. In this way, it is not even necessary for the categorizations to be made. Each student can be considered and taught in the most effective way without the need for groupings: tailor teaching to different "categories" becomes possible, if needed.

(c) Students have equal chances in an e-learning course, while in a teacher-led training, the effectiveness of the training will always depend on the teacher/student relationship. Age, origin, gender, language, disabilities, and social background are some of the factors which can have an impact on this relationship. The impact on the course quality can be positive or negative but is never insignificant. The quality of an e-learning course on the other hand isn't impacted by this teacher/student relationship. The same content is delivered to every student (in the best courses, the same content is delivered to every student having the same profile). Social origin, appearance, nationality does not influence the quality of the course delivered to the student. e-Learning gives all those who have access to the course the same chance to learn the concepts or acquire the skills taught.

In spite of all the promises of e-learning, it does not come without challenges. On a very basic level, there is one prerequisite, and this is the field where new inequalities are possible, and will be a reality for some decennia. "The computer infrastructure [...] is the basic prerequisite" (De Coutere et al. 2006). Having access to the necessary hardware (a computer or any other electronic device supporting flash such as: PDA, GSM, PodCast...) and having the skill to use it will define on which side of the Digital Divide (see http://www.itu.int/ITU-D/digitaldivide/\#note) the student is. Students on the same side of the Digital Divide have equal chances. In the same order of idea, e-learning is one of the means used to reduce the Digital Divide as developed for example in the $\mathrm{S}^{2} \mathrm{NET}$ project. ${ }^{2}$ The $S^{2}$ NET project, which is co-financed by the European Commission, aims at promoting e-learning in order to prevent old and new forms of social exclusion.

(d) In professional environments, e-learning is mostly used for IT and Language courses. While it might sound logical to use computer-based-trainings to learn about IT, it is less obvious how students can learn a language in front of a computer. It is true that learning a language is a matter of practice, and that's why the e-learning solution is then integrated into blended learning (combination of multiple approaches to learning. Examples include combinations of technology-based materials, face-to-face sessions and print materials).

Blended learning allows the student to improve his reading and listening comprehension, learn the grammar, complete some drill exercises... through the e-learning application while the mentor or instructor focuses on pronunciation and writing skills.

But even without blended learning, e-learning presents interesting opportunities for language learning. For example, its flexibility and anonymity:

Flexibility: When learning a language, it is more important to study a small piece of information on a regular basis than a large amount from time to time. The challenge then is to provide small courses that can be accessible whenever the student wants or is able to study. This is the reason why international companies use e-learning for teaching languages to their employees (example: Everyday English developed by IBM Europe-small e-learning courses developed on a daily basis). The student can follow the course while commuting in the train, at the office, during lunchtime or even in the evening at home. The

2 '2004-e-learning me included-How to use e-learning as a tool for social inclusion', see http://www.be-odl.org/images/res/_Toc97467133 (21 Aug 2006). 
flexibility offered by e-learning increases daily student attendance, which is essential for retention.

Anonymity: The absence of a teacher or mentor is often considered as a weakness of elearning. In this particular case it can actually be strength, particularly for students who lack self-confidence (bad accent...) and wouldn't dare speak up in the foreign language in a classroom setting. The best language e-learning courses are built in with a voice recognition system allowing the application to compare the student's pronunciation to a pattern.

And let us not forget that native speakers and learners can be brought into direct contact with one another through technology. One can work on language skills using authentic language materials produced by native speakers and chosen according to one's own interests, simply by searching the internet.

(e) Finally, e-learning may help to decode the www images and their impact on interethnic relations and social cohesion. It can't really impose specific meanings, but it can give a platform for discussion; it can give examples where meanings were (in)voluntary misconstrued and individuals can practice having their first reactions disconfirmed; what was intended vs. what was interpreted... In this sense, it may be helpful for social cohesion. The web will surely open new structures of cohesion, new boundaries between new and different types of groups. It will be important to understand its working. IT certainly makes information more broadly accessible, and thus actions of influential as well as ordinary individuals are more able to make a far-reaching and significant impact, are more open to scrutiny, and come with a greater risk of offending someone, etc. We will have to become more aware of this and take responsibility to people of other backgrounds, because we can no longer assume that people beyond our immediate physical vicinity won't be aware of or affected by what we say or do... nor can we assume that they can't do anything about it!

However, although technology offers many promises, it is not a simple answer or a quick-fix to any educational problem. It does little good for a school to install state-of-theart teleconferencing equipment and distance-learning facilities if there are no specific plans for how this will be used.

Ideally, not only the school but the surrounding community will benefit from investment in technology. "Colleges and universities around the world are finding that innovative elearning solutions can help them not only enrich curricula but also greatly expand their institutions' reach and resources" (IBM 2006a). The use of e-learning can allow educational facilities to offer their educational benefits to a greater number of people, and to help their surrounding communities through capacity-building even of those who are not officially registered students. In this way, schools could become even more instrumental in training a market force of skilled workers ready to take on the challenges of an everchanging economy.

Some of the latest technologies being designed for businesses include "presence" technologies, allowing those seeking information to contact relevant experts with questions, and individually customized courses, built on demand, to train workers in exactly what they need, using pre-existing components reordered to fit the specific situation (IBM 2006b). These technologies, although currently applied mostly in business scenarios, also hold a great deal of promise for education.

\section{Europe's Educational Responses for Interethnic Cohabitation}

Given the recent developments and challenges, it is now a major task not only to provide pupils (and teachers!) with access to the possibilities of the new global electronic space, 
but also to respond adequately to the various cultural and social dynamics that have been generated in its wake. These dynamics acquire their multilayered meanings partly independently from, but partly also linked up with ICT culture. In what follows we will give a short overview of some of the ways in which these new challenges are currently met in the European context, even though some of these measures have not been a response to the global ICT culture, but have been taken with a view to European unification.

\section{Socrates-Dealing with Growing Linguistic Complexity}

The European Socrates programme, based upon articles 149 and 150 of the Treaty of European Union, aims at reinforcing the European dimension of education and facilitating broad, transnational access to European educational resources, at improving the knowledge of the languages of the European Union, and in particular of the smaller and lesser taught languages, at stimulating educational cooperation and mobility and at studying matters of common interest. A first phase of the Socrates programme ran from 1995 until 1999. The programme is now nearing the end of its second phase, which runs from 1 January 2000 until 31 December 2006.

Two programmes deserve our particular attention in the Socrates project, since they directly touch the subject of this paper: the Erasmus programme (which is partially related to student migrations in general) and the Language Awareness programme with the Language Portfolio. These programmes are Europe's most tangible tools for coping with ethnic and cultural diversity.

\section{Erasmus}

The ERASMus programme (European Community Action Scheme for the Mobility of University Students), is enjoying increasing popularity. Statistics on the Socrates Internet site show that over a period of approximately 10 years-from the academic year 1993/ 1994 until the academic year 2003/2004 - the annual total of Erasmus students has more than doubled to 135,586 . This increase translates into a gradual to steep increase in the total number of outgoing students in all countries save the United Kingdom, where the total number of outgoing Erasmus students has slowly decreased since 1999/2000.

This remarkable overall increase is not only due to a generalized increased mobility, but also to the fact that in the above mentioned period a number of Associated Countries from Central and Eastern Europe joined the Erasmus programme, bringing the total number of participant countries to 31 in 2000. The number of outgoing students is growing most rapidly in the new EU Member States and in the candidate countries. Nevertheless, the initially envisaged goal of ten per cent mobility has not yet been achieved (King 2002, p. 99) and does not seem to be within easy reach.

\section{Language Programmes}

The European Union and the Council of Europe support a variety of programmes aiming at multilingualism. Examples include LINGUA and the projects of the European Centre for Living Languages in Graz, a COE institution (see: Janua Linguarum). However, it was not until the launch of the European Commission-backed Lingua Action D programme, with its 
research programme Evlang (1997-June 2001), that an official 'language awareness' project for improving pupils' sensitivity to multilingualism truly took shape in five European countries (Austria, Spain, Italy, France and Switzerland). The main aim of this project was to encourage teachers to use resources for multilingualism in their normal lessons. As already stated, ICT technology may become very useful in this kind of programmes.

In the framework of the new Europass, the Council of Europe is promoting the language portfolio (Council of Europe 2004; see also: www.edu.fi/julkaisut/tolppa.pdf).

The Europass is a European instrument aimed at increasing the transparency of people's education, internships or learning experiences, and hence also to improve language knowledge in the European Union. Since 2005 it provides the opportunity to create a single folder containing a CV, a language portfolio and diploma or certificate supplements (http://www. europass.cedefop.europa.eu/europass/home/hornav/Introduction/navigate.action).

\section{Intercultural Citizenship Education}

Education is considered to play a crucial role in nation-building everywhere in the world, in the sense that it passes on a state's 'national culture' and its values to the next generations. Likewise, it is education that has been singled out as one of the preferred tools for integrating migrants into the host society. Therefore, an important way in which education has responded to the increasing diversity in society is by offering a type of 'citizenship education' that prepares pupils for life in a culturally diverse society.

A common characteristic of these types of education is that they use a number of new teaching strategies and adapted study materials to foster a better understanding between various (ethnic) groups and individuals in society, thereby taking into account different cultural perspectives (see Luciak 2004, p. 87).

Several European countries have included these strategies in the national curriculum in some way. Austria, for example, introduced an 'integral principle of intercultural education' in the early 1990s, and in the Flemish community of Belgium, the decree on Equal Opportunities in Education has a strong intercultural component. However, despite the efforts, experts in various countries report a number of shortcomings, from poorly prepared teachers (Austria, the Netherlands, France), through a focus on minority pupils only (France), to applying an outdated model of intercultural education (Greece) (Luciak 2004, pp. 87-93). As yet there is no consensus among educational experts and policymakers on how intercultural education is best approached.

Of the various programmes discussed above (Socrates with its components, and intercultural citizenship education), the European Union and the European countries invest most of all in the Erasmus Programmes. This signals two priorities: a top-down approach, and a special attention to interuniversity contacts (important as these are in the development of a transnational, intra-European economic and intellectual life).

\section{Combating Deprivation}

Education experts have come to realize that citizenship education and language courses alone are insufficient as a remedy for diversity-related problems. The 2003 round of the Programme for International Student Assessment (PISA) has, for several countries, demonstrated a link between pupils' socio-economic background and their school performance. 
Results of PISA's pupils survey suggest that "in countries where the educational and socioeconomic status of immigrant families is comparatively low, the performance gaps between students with and without migrant background tend to be larger" (OECD 2004, p. 171). Moreover, when pupils' socio-economic background is controlled for, the migration factor becomes a less significant determinant of school performance. This implies that educational policy also has to focus on combating socio-economic deprivation, which is what various programmes across Europe try to do, even if often no systematic measures to combat deprivation are taken at the national educational policy level.

\section{Concluding Remarks}

In this time of profound social and ethnic diversification of migrations in Europe, in which the World Wide Web has become part of European ecology in a decisive and definitive way, multilayered identifications have become the norm. The impact of the Internet on these identifications has become very strong, affecting both the perceptions of the "self" and those of the "other". This creates educational challenges, but at the same time it offers elements of solution. Although we are dealing with a Europe-wide phenomenon here, we have seen that at the European level, for example, no specific educational strategy has been developed to deal with it. Existing interventions have a predominantly top-down character and do not show signs of integrated scenarios. Rather, they are patchy in their response to the challenges of globalization.

And yet a European policy in this area would not only be perfectly possible but also most welcome at a pre-university level. Teaching pupils how to decode interethnic discourse, helping to structure interethnic dialogue-including the intra-European socialization of distant partners, and 'in vivo' language training are just some of the obvious examples of educational measures in which the Internet could play a prominent part.

When we see that the E.U. invests most of its finances, for e-learning programmation, in the top-down approach, the question arises if this doesn't need complementary incentives? And these incentives should focus on the learner beginning at a very young age. Today, education is still too often focused on the teacher's knowledge. Even at the university level information is too often delivered by the professor while students have a rather passive role to play. Students are asked to assimilate the information and be able to repeat it, but we too rarely climb into Bloom's taxonomy pyramid and ask the student to Analyse, Synthesize or Evaluate (Bloom 1956).

Existing and new technologies bring us new tools which allow for a learner-centred approach: (a) the WWW, the Forums, Google... give the student the opportunity to find the information he would like to get; (b) the e-portfolios go even further. E-portfolios are repository based on the internet which "students can create and customize for academic, career, or personal uses; maintain their plan of study; and share their work, goals, and achievements with advisors, career counsellors, and employers" (see http://www. eportfolio.org). It's the student's decision to fill it in and it shows the learning path he has accomplished. The communities and wikis (wikipedia, wikibooks) invite the learner to contribute and become a teacher to others. The wikis and forums, contribute to a better understanding between individuals in society. When writing a manual, book or article, the individual is not judged on his origin, name, age... as he can participate anonymously, but on its contribution. Communities of interests regroup participants from all over the world. Virtual networks are created regardless of prejudice. 
Technology has an important role to play both in the acceleration of the changes we must face, and in creating the solutions that will be needed. New migrations, ethnic and social diversification have become our new European reality - a reality that entails a risk of withdrawing into narrow nationalisms and fundamentalisms, into xenophobia and racism. Globalization and Internet culture have to a certain extent helped to create these tendencies, but they can also make a real contribution to combating such trends and they may even help to deflect them into a more open humanism. In education, they may do so by taking the existing diversity in society-including its potential as well as its challenges-as a point of departure, which appears to be a valuable alternative to an approach aimed at fostering societal integration from above.

We should be excited about the possibilities offered by technological innovations. But we must also remain constantly aware of the importance of the role humanity has to play. If technology continues to connect us, we must continue to adapt ourselves to achieve a truly collaborative community working for the betterment of Europe and of humanity.

\section{References}

Anderson, B. (1983). Imagined communities: Reflections on the origins and spread of nationalism. London: Verso.

Appadurai, A. (1996). Modernity at large. Minnesota: University Press.

Barré, R., et al. (2003). Diasporas scientifiques. Scientific diasporas. Paris: IRD editions.

Barth, F. (1994). Enduring and emerging issues in the analysis of ethnicity. In H. Vermeulen \& C. Govers (Eds.), The anthropology of ethnicity. Beyond 'ethnic groups and boundaries' (pp. 11-32). Amsterdam: Het Spinhuis.

Basch, L., Glick-Schiller, N., \& Szanton-Blanc, C. (1995). Nations unbound: Transnational projects, postcolonial predicaments, and deterritorialized nation-states. New York: Gordon and Breach.

Baumann, G. (1999). The multicultural riddle: Rethinking national, ethnic, and religious identities. London: Routledge.

Bloom, B. S. (1956). Taxonomy of educational objectives: The classification of educational goals. New York: Longmans, Green.

Carling, A. (Ed.). (2006). Globalization and identity. Development and integration in a changing world. London: Tauris.

Castells, M. (1996). The rise of the network society. Oxford: Blackwell.

Coatsworth, J. (2004). Globalization, growth, and welfare in history. In M. Suarez-Orozco \& D. B. QinHilliard (Eds.), Globalization. Culture and education in the new millennium (pp. 38-55). Berkeley: University of California Press.

Council of Europe-Language Policy Division. (2004). European language portfolio (ELP). Principles and guidelines, with added explanatory notes (version 1.0). Council of Europe DGIV/LANG (2000) 33 rev.1. Revised in June 2004, 10 pp. Strasbourg: CoE.

De Coutere, B., Baten, L., \& Viaene, S. (2006). 6C-learning: A pragmatic framework for 2nd generation e-learning projects. See http://www.6c-learning.org/. Accessed 21 Aug 2006.

Giddens, A. (1999). Runaway world: How globalization is reshaping our lives. London: Profile Books.

Grillo, R. D. (1998). Pluralism and the politics of difference: State, culture, and ethnicity in comparative perspective. Oxford: Clarendon.

Heyneman, S. (2003). Education, social cohesion, and the future role of international organizations. Peabody Journal of Education, 78(3), 25-38.

IBM. (2006a). Inspired: Real stories from government, education and health care. Accessed through www.ibm.com/learning. Accessed 20 Oct 2007.

IBM. (2006b). Learning infrastructure: Architecting a formal and informal learning environment. IBM Learning Solutions Executive Brief. Accesses through www.ibm.com/learning. Accessed 20 Oct 2007.

IOM. (2003). World migration 2003: Managing migration: Challenges and responses for people on the move. Geneva: IOM World Migration Report Series, 2.

King, R. (2002). Towards a new map of European migration. International Journal of Population Geography, 8, 89-106.

Luciak, M. (2004). Migrants, minorities and education. Documenting discrimination and integration in 15 member states of the European Union. Vienna: EUMC. 
Miyares, I. (2004). From exclusionary covenant to ethnic hyperdiversity in Jackson Heights, Queens. Geographical Review, 94(4), 462-483.

OECD. (2004). Learning for tomorrow's world: First results from PISA 2003. Paris: OECD.

OECD/SOPEMI. (2005). Trends in international migration. SOPEMI 2004 Edition.

Portes, A. (Ed.). (1998). The economic sociology of immigration. New York: Russell Sage.

Putnam, R. (2001). Bowling alone. New York: Simon and Schuster.

Reimer, J. (2005). Total share: 30 years of personal computer market share figures. Retrieved from www.arstechnica.com. Accessed 20 Oct 2007.

Robertson, R. (1992). Globalization. Social theory and global culture. London: Sage.

Shen, W. (2005). A study on Chinese student migration in the United Kingdom. Asia-Europe Journal, 3, 429-436.

Suarez-Orozco, M., \& Qin-Hilliard, D. B. (Eds.) (2004). Globalization. Culture and education in the new millennium (pp. 1-37). Berkeley: University of California Press.

Vanlangendonck, M. (2002). Tourism as ethnic relations in Crete (Greece). An ethnographic outline. KOLOR, Journal on Moving Communities, Antwerp, 2, 61-76.

Vertovec, S. (2006). The challenges of super-diversity. EASA paper, September, abstract.

Xavier Inda, J., \& Rosaldo, R. (Eds.). (2001). Introduction: A world in motion. The anthropology of globalization: A reader (pp. 1-34). New York: Blackwell.

\section{Internet information}

Eurostat databases: Student mobility (tp05_1 and tp05_3), Number of foreign students in tertiary education (ISCED 5-6) by level of education, programme destination and country of citizenship (isced 5_6).

Erasmus/Socrates Internet page: http://www.europa.eu.int/comm/education/programmes/socrates/erasmus/ erasmus_en.html (01/03/2006). 